\title{
The effect of improved housing on indoor mosquito density and exposure to malaria in the rural community of Minkoameyos, Centre Region of Cameroon.
}

\section{Rachel Laure Nguela ( $\square$ rachelnguela@yahoo.com )}

Universite de Yaounde I Faculte de Medecine et des Sciences Biomedicales https://orcid.org/00000003-4036-2295 Jude D. Bigoga Universite Protestante d'Afrique Centrale Faculte de Theologie et des Sciences Religieuses

\section{Tedjou N. Armel}

Universite de Yaounde I

\section{Tallah Tayie Ngobiyo Esther}

Malaria Consortium-Cameroon Coalition Against Malaria

\section{Line Leukou Dongmo}

Malaria Consortium-Cameroon Coalition Against Malaria

Njeambosay A. Boris

Universite de Yaounde I

Tchouine Frederic

Malaria Consortium-Cameroon Coalition Against Malaria

\section{Riksum Kazi}

ARCHIVE Global

\section{Peter Williams}

ARCHIVE Global

Wilfred F. Mbacham

university of Yaounde I, Malaria Consortium-Cameroon Coalition Against Malaria

Rose G. F. Leke

Malaria Consortium-Cameroon Coalition Against Malaria

\section{Research}

Keywords: Improved houses, unimproved houses, Anopheles gambiae, An. funestus, malaria transmission, Cameroon, Anopheline density, EIR 
DOI: https://doi.org/10.21203/rs.2.18556/v1

License: (c) (1) This work is licensed under a Creative Commons Attribution 4.0 International License. Read Full License

Version of Record: A version of this preprint was published at Malaria Journal on May 3rd, 2020. See the published version at https://doi.org/10.1186/s12936-020-03232-6. 


\section{Abstract}

Background: Malaria control faces several threats. Alternative strategies to complement Long Lasting Insecticide-treated Nets and antimalarial therapy are therefore mandatory. This study evaluated the effectiveness of improved housing on indoor residual mosquito density and exposure to malaria-carrying Anophelines in Minkoameyos, a rural community in the center region of Cameroon.

Methods: Following the identification of housing factors affecting malaria prevalence in 2013, 218 houses were improved (screening of doors and windows, installing plywood ceilings on open eaves, closing holes on the walls and doors). Quarterly surveys were conducted in a sample of 21 improved and 21 non-improved houses from November 2014 to October 2015. Mosquitoes sampled by night collections on human volunteers were identified morphologically. Their parity status determined. Mosquito infectivity was verified through Plasmodium falciparum CSP ELISA. The average entomological inoculation rates were determined. A Reduction Factor (RF), defined as the ratio of the values for mosquitoes collected outdoor to those collected indoor was calculated in improved houses (RFI) and non-improved houses (RFN). An Intervention Effect (IE=RFI/RFU) measured the true effect of the intervention. Chi-square test was used to determine variable significance. The threshold for statistical significance was set at $P<0.05$.

Results: A total of 1113 mosquitoes were collected comprising: Anopheles (58.6\%), Culex (36.4\%), Aedes (2.5\%), Mansonia (2.4\%) and Coquillettidia (0.2\%). Amongst the anophelines were An. gambiae s.I. (95.2\%), An. funestus (2.9\%), An. ziemanni (0.2\%), An. brohieri (1.2\%) and An. paludis (0.5\%). An gambiae s.s. was the only Anopheles gambiae sibling found. The intervention reduced the indoor Anopheles density by 1.8 fold $(\mathrm{RFI}=3.99 ; \mathrm{RFN}=2.21 ; \mathrm{P}=0.001)$. The indoor density of parous Anopheles was reduced by 1.7 fold ( $R F I=3.99 ; R F N=2.21 ; P=0.04)$ and that of infected Anopheles by 1.8 fold (RFI=3.26; $\mathrm{RFN}=1.78 ; \mathrm{P}=0.04$ ). Indoor peak biting rates were observed between 02am to 04am in non improved houses and from 02am to 06am in improved houses.

Conclusion: Housing improvement reduced indoor residual anopheline density and malaria transmission. This highlights the need for Standardization and promotion of similar interventions to prevent malaria in comparable contexts.

\section{Background}

Malaria threatened nearly half of the world's population in 2012(1). A total of 198 million malaria cases were reported worldwide in 2013 (2). The disease is the leading cause of presentations at clinics and hospitalization in Africa. Malaria morbidity represented around $30-40 \%$ of all fevers registered in health centers with variations from less than $10 \%$ at the end of the dry season to more than $80 \%$ at the onset of the rainy season (3). The infection costed Africa, the poorest continent on the planet, about US\$12 billion in lost productivity and health expenditures, each year (4). Malaria is endemic in 43 sub-Saharan Africa countries. Cameroon is one of the seven with more than $25 \%$ of their population infected with malaria parasites (5). 
Despite growing effort by the government, malaria remains endemic throughout the country and continues to be one of the top three causes of morbidity and mortality, especially among children and pregnant women (6). Malaria transmission is influenced by climate and geography. The endemicity is worsened by increased drug resistance and inadequate use of vector control measures $(7,8)$. In 2013, Malaria was responsible for $28.7 \%$ of consultations and $49.8 \%$ of hospitalizations. It accounted for $22 \%$ of health facilities deaths across all age groups, with $45 \%$ of deaths in children less than five (9).

Malaria is transmitted to humans by the bites of infected female Anopheles mosquitoes (10). At least 48 species of Anopheles have been reported in Cameroon amongst which 17 are capable of supporting the development and propagation of malaria parasites. Amongst these are five major species (An. gambiae, An. colluzi, An. arabiensis, An. funestus, An. nili and An. moucheti). There rest play only secondary role in transmission. Global efforts to control malaria vectors have focused mainly on tools that rely on the use of insecticides such as long lasting insecticidal nets and indoor residual spraying. Although these methods have contributed enormously to curbing the disease burden, there have been wide and increasing reports of insecticide resistance in the major vector species $(11,12)$ as well as behavioral change towards the interventions (13-16). LLIN is the prioritized vector control tool in Cameroon. Its low ownership in households and inappropriate usage practices in the population are some of the reasons of the country's limited progress in malaria control (6). Therefore, the development of durable alternative strategies for malaria vector control is essential.

Housing is increasingly being recognized as an important determinant of health outcomes (17). Several studies have demonstrated the relationship between housing design and global health issues such as parasitic diseases and flooring material, respiratory diseases and indoor ventilation, vector-borne diseases and screening of openings. History in Europe portrays the potential for housing improvements as a legitimate strategy to effectively contribute towards malaria elimination $(18,19)$. Housing improvements through screening of windows and doors, closing of eaves and crevices, patching of walls and roofs help reduce malaria transmission (20-23, 23-25). In many African countries, studies have shown that the biting and feeding activity of the main malaria vectors increase at night, when humans are mainly indoors $(20-24,26-30)$. Therefore, houses with openings at the level of eaves, walls, windows, doors and/or ceilings will enhance mosquito entry, exposing its occupants to higher risks of malaria (31-34). In Cameroon higher malaria parasite prevalence and parasite density were recorded amongst individuals living in poorly constructed houses (wooden plank houses) compared to those in cement brick houses (35).

In Cameroon, typical housing in many areas has openings on the eaves, walls, windows, doors. This facilitates mosquito entry and increase exposure to infective bites. Preliminary baseline prevalence data prior to this study depicted individuals living in houses with features such as cement walls and presence of a ceiling to have lesser chances of becoming infected by malaria parasites compared to those in poorly constructed households (MC-CCAM, unpublished data). Against this backdrop, we sought to determine the effectiveness of improved housing on indoor residual mosquito density and exposure to malaria-carrying anophelines in the rural community of Minkoameyos in the Centre region of Cameroon. 


\section{Methods}

\section{Study area}

The study was carried out in Minkoameyos in the Nkol-Nkoumou health area and within the the Nkolbisson health district. It is located $25 \mathrm{~km}$ to the west of Yaoundé, the capital city of Cameroon. Minkoameyos is about $731 \mathrm{~m}$ above the sea level and georeferenced by latitude $11,42^{\circ}$ North and longitude $3,87^{\circ}$ East. The climate is Guinean Equatorial type with two dry seasons (July to August and November to February) and two rainy seasons (March to June and September to November) (36). The rainfall and temperature annual averages are $1650 \mathrm{~mm}$ and $24^{\circ} \mathrm{C}$ respectively with a relative humidity less than $80 \%(37)$. It is a rural community with a population of approximately 7150 inhabitants living in 710 households. There are averagely seven people and two children less than 5 years of age per household. Inhabitants are mainly constituted by indigenous population (Ewondo). The halogenic populations consists of Bassa, Bamileke, Bamoun and Eton. The main activities are small scale farming and small businesses. The only state corporation in the area is CAMWATER "Camerounaise des Eaux". As indicated by the baseline study, malaria is prevalent across all age groups. The disease is cited by the population as the most important in the area (MC-CCAM, unpublished data). Minkoameyos is in the south Cameroonian Equatorial forest strata, where Malaria transmission is perennial with An. gambiae s.l. being the major vector species and Plasmodium falciparum the predominant parasite species (38).

\section{Study design and housing modifications}

This was a longitudinal entomological study that lasted 12 months, from October 1 st 2014 to November 30th 2015. Mosquitoes were collected from both the intervention and control houses. Measures of the entomological indices for transmission in the two groups were compared for effectiveness assessment. The selection of households for the study was through a systematic sampling. It is described in Fig. 1.

Interventions consisted of modifications on the windows, doors, eaves, walls and roof to limit mosquito access into houses. A screened door with metallic netting and wooden frame was fabricated and installed on all existing doors leading to outside. Where the windows were hanging outside the house when opened, a second window with metallic netting and wooden frame was fabricated and installed on the existing windows frames. Where the windows were hanging inside the house when opened, or could be opened without hanging at all, a piece of metallic netting was adapted to the outer part of the window frame, using wooden cover joints. Plywood was installed on all opened eaves. Existing holes on the roofs and walls were closed using material initially used by house owners.

Control houses were unmodified houses in the community. Both study arms were found in the same community. They therefore had the same source of information regarding malaria prevention. They were attending the same health facilities for malaria treatment.

Field collection and processing of Adult anophelines. 
Mosquitoes were sampled every month from improved and unimproved houses, using the human landing catch (HLC) method. Every month, HLC were performed for two consecutive nights from 06:00 pm to 06:00 am. Mosquitoes were collected indoors and outdoors in three randomly selected houses (at least $50 \mathrm{~m}$ apart) each night, with rotation between houses at different places in order to cover every section of the village. A team of four trained volunteers collected samples in each house. Two collected during the first half on the night and the others during the second half of the night. During mosquito collection, one collector sat inside the house (indoor) and the other on the veranda (outdoor). They collected mosquitoes as soon as they landed on their exposed lower limbs. Only adequately trained volunteers were allowed to collect mosquitoes. In order to avoid bias due to differential attractiveness, the two volunteers swapped locations (indoor and outdoor) every two hours during their shifts. Every two hours, Entomologists visited the teams to ensure the change in position and collection of mosquitoes. These mosquitoes were sorted by genus and the anophelines identified morphologically using keys described by Gillies\&De Meillon (1947) and Gillies \& Coetzee $(1987)(39,40)$. The ovaries of all unfed females were dissected for parity determination as described by Detinova et al. (1962) (41). All dissected and those undissected mosquitoes were individually stored desiccated in tubes for further laboratory analyses.

\section{Laboratory processing of Anophelines}

A proportion of the collections belonging to the An.gambiae complex was further identified to species level using molecular assays. Genomic DNA of each individual specimen was extracted using DNAzol protocol (42) and PCR amplified to determine species according to Favia et al. (1997)(43)

The head and thorax portions of each female Anopheles collected were separated from the rest of the body. They were homogenized in grinding buffer $(0.5 \%$ Casein, $0.1 \mathrm{~N} \mathrm{NaOH})$ to detect the presence of $P$. falciparum circumsporozoite protein (CSP) by enzyme-linked-immunosorbent assay (ELISA) $(44,45)$. Infection rate for each specy was calculated and the entomological inoculation rate determined. To minimize false positive CSP ELISA, only high absorbance readings were considered (mean plus three standard deviations of the negative controls).

\section{Data analysis}

For each house, information on each mosquito collected from field and laboratory procedures during each night catch was recorded using a questionnaire. The data were entered into the Epi Info ${ }^{\text {TM }}$ software. Two trained data entry clerks entered each of the questionnaires separately. One final clean data base was prepared and used for statistical analysis.

Man biting rate (ma) was calculated as the average number of bites from Anopheles species received per person each night of collection. Infection Rate (IR) was calculated as the proportion of Anopheles species tested positive for P. falciparum CSP by ELISA. The Entomological Inoculation Rate (EIR) was determined as the product of the Infection Rate (IR) and the man biting rate (ma). A Chi-square test was used to determine variable significance. The threshold for statistical significance was set at $P<0.05$.

With regards to measures of the intervention effect, the following parameters were considered: 
a) Reduction Factor (RF) given as the ratio of the values for mosquitoes collected outdoor to those collected indoor. (RFI = Reduction Factor in improved houses and RFN = Reduction Factor in non-improved houses);

Where RFI > 1, intervention had a reduction effect between outdoor and indoor on a specific entomologic index;

$\mathrm{RFI}<1$, intervention had an exposing effect between outdoor and indoor on a specific entomologic index;

b) The Intervention Effect $(\mathrm{IE})=$ Measure of the true effect of the intervention in the population.

\section{IE $=$ RFI/RFN}

Where IE $>1$, meant the intervention has protective effect in the overall population (on the entomological index of interest);

Where IE $<1$ meant the intervention is non-protective in the overall population (on the entomological index of interest).

\section{Results}

\section{Sample}

Our sample was constituted of 21 improved and 21 non-improved houses.

\section{Mosquito composition and density}

As shown in table 1, a total of 1,105 mosquitoes were collected, comprising of 647 (58.6\%) Anopheles sp., 402 (36.4\%) Culex sp., 28 (2.5\%) Aedes sp. and 2 (0.2\%) Coquellitidia sp. The Anophelines were constituted of An. Gambiae s.l. (95.2\%), An. funestus (2.9\%), An. brohieri (1.2\%), An. paludis (0.5\%) and An. ziemanni (0.2\%). Of the 647 anophelines, 154 (23.8\%) was collected indoors comprising An. gambiae s.l. 149(96.7\%), An.funestus 4 (2.6\%), and An. ziemanni1(0.6\%). 493(76.2\%) were collected outdoor, made up of An. Gambiae s.l. 467(94.7\%), An. Funestus 15(3.04\%), An. paludis 3(0.6\%) and An. brohieri81.6(\%). An. Gambiaes.s. was the only member of the An.gambiae complex found.

With regards to the proportion of Anophelines collected based on housing status (improved/nonimproved), 429 were collected from improved houses, with $20.04 \%$ from indoor spaces and $79.96 \%$ from outdoor spaces. We collected 218 from non-improved houses with $31.2 \%$ from indoor and $68.8 \%$ from outdoor spaces.

\section{Night biting cycle of the anophelines}

Generally, the average man biting rate was observed to increase gradually between $6 \mathrm{pm}$ to $4 \mathrm{am}$, peaking between 2am to $4 \mathrm{am}$ and then slowly declining to 6am (Figure 2). The overall man biting rate for the 
Anopheles was 0.098 bites per person per night (b/p/n). An gambiae s.l. was the most aggressive specy, representing $95.2 \%$ of the total number of bites $(0.094 \mathrm{~b} / \mathrm{p} / \mathrm{n})$ with peak biting hours between 2am to $4 \mathrm{am}$ regardless of the place of bite. Despite the small number collected compared to An. gambiae, the peak biting hours for An. funestus, was also observed at the same period both indoor and outdoor spaces (Figure 2).

\section{Parity rates:}

A total of 488 female Anopheles were dissected for parity status with an overall parity rate of $61.3 \%$ (Table 1). Observing by species, the parity rates were $62.4 \%$ (290/465), 53.8\% (7/13), 100\% (1/1) and 12.5\% (1/8) for An. gambiae, An. funestus, An. ziemanniand An. brohieri respectively.

\section{Infection and entomological inoculation rates:}

A total of 615 female Anopheles mosquitoes were processed to ascertain the presence of $P$. falciparum circumsporozoite antigen by CSP-ELISA. Of these, 210 were infected, giving an overall circumsporozoite antigen rate of $34.2 \%$ (Table 1). Despite The circumsporozoite antigen rate for An. gambiae (33.6\%), the most abundant specy, was lower compared to An. Funestus (52.6\%). The lone An. ziemanni and 3 An. paludis collected were infected. None of the An. brohieri captured was infected. The intervention did not reduce indoor sporozoite infection rates of all Anopheles $(\mathrm{IE}=1.1)$. It however reduced relative indoor sporozoite infection rates of $A n$. gambiae by 1.8 fold.

The overall average EIR was 0.29 infective bites per person per night (ib/p/n) with An. gambiae and An. funestus contributing to most of the transmission (Table I).

\section{Effect of house improvement on entomological indices.}

\section{Effect of house improvement on mosquito density}

In the improved homes, the relative number of indoor Anopheles significantly reduced by 1.8 fold ( $R F I=3.99 ; R F N=2.21 ; P=0.001$ ) compared to the control group. In these improved homes, the relative number of An. gambiae entering houses by 1.7 fold (RFI=3.81; RFN=2.26; $P=0.004$ ). Although the number of An. funestus collected indoors was 12 fold lower than the number collected outdoors in the improved, this effect was not statistically significant $(R F I=12 ; R F N=1 ; P=0.07)$ probably due to the small sample size in this study (Table 2).

\section{Effect of house improvement on mosquito parity status}


Table 3 summarizes the effect of the intervention on the number of parous specimens found for each Anopheles species and their parity rates. Improving houses was associated with a reduced number of all parous Anopheles found indoors by 1.7 fold $(\mathrm{RFI}=4.48 ; \mathrm{RFN}=2.67 ; \mathrm{p}=0.05)$. The relative number of parous An. gambiae significantly reduced by 1.8 fold $(R F I=4.32, R F N=2.63 ; p=0.03)$. The intervention was associated with reduced the indoor parity rates of $A n$. gambiae by 1.3 fold; and consequently for all Anopheles species by 1.2 folds (Table 3 ).

\section{Effect of house improvement on Entomological Inoculation Rate}

Table 4 shows the indoor and outdoor variation in entomological inoculation rates (EIR) in the two groups of houses. It was observed that improving the houses led to a reduction of the number of infective bites received per person per night indoors. The relative reduction was 1.7 fold $(R F I=4.84, R F N=2.81)$ for all Anopheles and 1.6 fold (RFI=4.75; RFN=3.04) for An. gambiae.

\section{Discussion}

\section{Entomological indices}

During this study, most of the Culicine specy collected was Culex. Its presence may be due to the proximity of the study site near to the city which, because of pollution, constitutes a suitable habitat for its development. This high density constitutes an important cause of nuisance by these mosquitoes in the community $(46,47)$. An. gambiaes.s. and An. funestus were the main Anopheles species collected followed by An. ziemanni and An. paludis, with an appearance of An. brohieri.

The man biting cycle observed was principally induced by An. Gambiae s.s. known as the most aggressive specy (48). It peaked between 2am to $4 a m$ regardless to the place of bite. Gillies and De Meillon earlier described peaks from $10 \mathrm{pm}$ to 02am (Gillies \& B, 1968). This difference shows the ability of Anopheles species to change their blood-feeding cycle. It could be due to the lack or non compliance with the use of LLINs. The nets were older than 4 years might have lost their efficacy.

The high parity rate observed especially among the major vector species, An. Gambiae s.s., indicates that there is the gradual accumulation of ageing adult population over time in this area. This is epidemiologically dangerous, as the mosquitoes will frequently blood-feed on humans and be able to develop and transmit malaria(LONDON Applied Science publishers, 1976) even more than once. This study also suggests that the anti-vector measures are not well implemented or that the vectors have developed startegies to avoid the intervention and survive longer. Hence, population needs to be properly educated on the use and role of LLINs in malaria prevention.

The prevalence of sporozoite positive mosquitoes in our sample is $34.2 \%$ with an EIR of $0.808 \mathrm{ib} / \mathrm{P} / \mathrm{n}$. Thus, individuals living in Minkoameyos during the study period were at the risk of receiving 0.808 infectious mosquito bites per night. The abundance and circumsporozoite antigen status of An. Gambiae 
S.s. and An. funestus confirm their role as the major malaria vectors in Cameroon, particularily in periurban areas $(46,49)$. An. ziemanni and An. paludis, are known as secondary malaria vectors, due to their minimal contribution in malaria transmission in localized areas. This has been confirmed in our study. The two vectors can therefore contribute to maintaining transmission even on a small scale over a long period of time in this locality. However, due to their low density in this study, their actual contribution to malaria transmission nedds to be investigated further(50). None of the An. brohieri was found positive by CSP ELISA and could be suggested to have no role in malria transmission in this locality.

\section{Effect of house improvement on entomological indices}

The effectiveness of screening homes in reducing malaria incidence has been demonstrated in several studies in sub-Saharan Africa(28,51). Limiting vector entrance into the houses(52) will reduce vectorhuman contact and consequently the and infection rates (30). An. Gambiae s.s., one of the most prevalent and important vectors of malaria in sub-Saharan Africa constituted $95.2 \%$ of the total Anopheles species collected. Our findings show that the appropriate modifications of houses can lead to a significant decrease in the indoor density of malaria vectors as well as in the risk of exposure during main vector feeding hours of the day by up to $50 \%$. Higher reduction rates have been reported in several areas such as: The Gambia, where improved houses through installation of insect-screen ceiling reduced house entry of An. gambiae mosquitoes by about $65 \%$ and $80 \%$ in 1987 and 2003 respectively(30); in southern Mozambique, covering gabble end of houses with either untreated mosquito netting, shade clothe and deltamethrin impregnated shade clothe reduced house entry of An.gambiae by $84 \%, 69 \%$ and $76 \%$ respectively(53). In a rice irrigation scheme area in lowlands of western Kenya, papyrus mats ceiling modification reduced house entry of Anopheles gambiae s.I and Anopheles funestus densities by 78 to $80 \%$ and $86 \%$ respectively compared to unmodified houses(52).

When comparing the night biting cycle of the indoor and outdoor mosquitoes, there was a significant reduction in mosquito abundance during the night, especially between $10 \mathrm{pm}$ to $06 \mathrm{am}$. This could be because An. gambiae is well adapted for entering houses through the eaves, since it flies upwards when encountering a vertical surface(40). The housing improvements implemented became significant barriers to mosquito entry into the house during their feeding times and during human resting time indoors.

The relative number of indoor parous An. gambiae reduced significantly by 1.8 folds in improved houses. The indoor density of infected Anopheles mosquitoes (all species) also reduced by 1.8 folds in improved homes. These results highlight the trends and correlation between improved housing and the decrease in risk of exposure to malaria-carrying vectors. Infection rates and EIR were also lower in intervention houses; this may be due to factors such as household environment, and population knowledge, living and treatment seeking habits. Housing improvements shielding home residents from exposure to and contact with potentially infected vectors have shown to be a highly acceptable strategy often welcomed by the communities and households receiving it (54). The additional comfort, improved aesthetics and noticeable relief from vectors could be the reason for such level of acceptance. The good uptake of this 
vector-control strategy indicates that there is important potential to scale-up similar interventions elsewhere in places of need. This study highlights the need for integrated approach to malaria control and further research on the effect of house improvement on malaria incidence rates, while controlling for other factors mentioned above.

This study presents certain limits. It did not account for socio-economic determinants of health such as wealth and the possession of bednets which may considerably impact the number of vectors in the catches. Furthermore, the study did not control for LLIN position. Despite these limits, relevant and important conclusions as well as significant trends can be drawn from this study.

\section{Conclusion}

The screening and repairs made to the houses reduced vectors entry into the house as well as chances of indoor infective bites. This study conducted in a semi-urban area of Cameroon, with perennial malaria transmission further confirms the potential effectiveness of housing improvements as a sustainable and potential malaria control strategy for high endemic areas. Larger scale studies including both entomological, socio-anthropological factors and parasitological and data collection across all age groups will help highlight and guide insights on innovative strategies that can promote housing modifications as a strategy to fight against malaria.

\section{Declaration}

\section{Ethic Approval and consent to participate}

Ethical clearance was obtained from the National Ethics Committee of Cameroon (CNE No: 2013/06/343/CNERSH/SP). Participation in the study was voluntary and all matters relating to the study were clearly explained to the participants prior to obtaining the informed consent. Consent of household heads was sought prior to using their houses for mosquito collection. Participation in mosquito collection was also voluntary and only those adequately trained and who mastered the collection process were retained. They were closely monitored and treated accordingly in case they contracted malaria thereafter.

\section{Consent for publication}

Not Applicable

\section{Availability of data and material}

The datasets used and/or analysed during the current study are available from the corresponding author on reasonable request. 


\section{Competing interests}

The authors declare that they have no competing interests

\section{Funding}

The research was realized as part of collaboration between ARCHIVE Global New York, MC-CCAM and the BTC of the University of Yaoundé I, which was funded through a grant from the UBS Optimus Foundation to ARCHIVE Global.

\section{Authors' contributions}

RLN: Conception of study and experimental design, data collection, data analysis and interpretation as well as article write-up and project coordination. JDB: Conception of study and experimental design, coordination of field and laboratory processing of mosquitoes, data interpretation as well as article write up. TNA: Data collection, analysis and article write up. DL: Data collection and analysis. NAB: Data collection, analysis and article write up. TF: Statistical analysis. RK: Conception of study and experimental design. PW: Conception of study and experimental design, critical reading of the manuscript. ET: Conception of study and experimental design, critical reading of the manuscript. WFM: Conception of study and experimental design, critical reading of the manuscript. RGFL: Conception of study and experimental design, critical reading of the manuscript, supervision of the team. All the authors read and approved the final manuscript.

\section{Acknowledgement}

We are grateful to the Minkoameyos community, for their frank collaboration. We are thankful to the National Malaria Control Programme and the University of Yaoundé I for their material and technical support. We thank the research team from the National reference Unit for Vector Control at the Biotechnology Centre of the University of Yaoundé I for their support in conducting the field and laboratory analysis. We would also like to appreciate the support from the entire ARCHIVE Global and MCCCAM teams for their support in logistic and coordination support.

\section{Abbreviations}

An: Anopheles

ARCHIVE: Architecture for health in Vulnerable Environment

$\mathrm{b} / \mathrm{p} / \mathrm{n}$ : bites per person per night . 
BTC: Biotechnology Center

CAMWATER :

CSP: Circumsporozoite Protein

DNA:Deoxy ribonucleic Acid

DNAzol:

EIR : Entomological Inoculation Rate

ELISA: Enzyme-Linked-Immunosorbent Assay

HLC: Human Landing Catch

IE: Intervention Effect

IR : Infection Rate

LLIN : Long Lasting Insecticide-treated Nets

m.a : Man Bitting rate

n/a: Not applicable

$\mathrm{NaOH}$ : Sodium Hydroxyde

NMCP: National Malaria Control Program.

p.: Plasmodium

PCR: Polymerase Chain Reaction

RF: Reduction Factor

RFI = Reduction Factor in Improved houses

RFN = Reduction Factor in Non-improved houses

s.l.:

s.s:

Sp.:

\section{References}


1. WHO. World Malaria Report 2012. 2012.

http://www.who.int/malaria/publications/world_malaria_report_2012/report/en/. Acessed 21 Jun 2018.

2. WHO. World Malaria Report 2013. 2013.

http://www.who.int/malaria/publications/world_malaria_report_2013/report/en/. Assessed 21 Jun 2018]

3. WHO. Malaria vector control and personal protection: report of a WHO Study Group [on Malaria Vector Control and Personal Protection; Geneva, 12 - 14 March 2004 Geneva. World Health Organiization 2006, 62 .

4. Anderson L, Simpson D, Stephens M. Effective Malaria Control Through Durable Housing Improvements. 2014. http://www.habitat.org/sites/default/files/malariahousing-combined-print.pdf. Accessed 26 Feb 2016.

5. WHO. World Malaria report. World Health Organiization. 2012.

6. Ganguly S, Saha P, Guha SK, Das S, Bera DK, Biswas A, et al: In vivo therapeutic efficacy of chloroquine alone or in combination with primaquine against vivax malaria in kolkata, west bengal, india, and polymorphism in pvmdr1 and pvcrt-o genes. Antimicrobial Agents and Chemotherapy 2013, 57(3):1246-51.

7. Nkuo-Akenji T, Ntonifor NN, Ndukum MB, Abongwa EL, Nkwescheu A, Anong DN, et al.: Environmental factors affecting malaria parasite prevalence in rural Bolifamba, South West Cameroon.Afr J Health Sci. 2006, 13(1-2):40-6.

8. WHO: World Malaria Report 2008. 2008.

9. NMCP Cameroon: Plan strategique national de lutte contre le paludisme 2014-2018, 2014. 106p.

10. WHO: Malaria entomology and vector control, guide for participants. 2013.

11. Toé KH, N’Falé S, Dabiré RK, Ranson H, Jones CM : The recent escalation in strength of pyrethroid resistance in Anopheles coluzzi in West Africa is linked to increased expression of multiple gene families. BMC Genomics 2015, 16(1):146.

12. Trape J-F, Tall A, Diagne N, Ndiath O, Ly AB, Faye J, et al.: Malaria morbidity and pyrethroid resistance after the introduction of insecticide-treated bednets and artemisinin-based combination therapies: a longitudinal study.Lancet Infect Dis. 2011, 11(12):925-32.

13. Gatton ML, Chitnis N, Churcher T, Donnelly MJ, Ghani AC, Godfray HCJ, et al.: The importance of mosquito behavioural adaptations to malaria control in Africa. Evolution 2013, 67(4):1218-30.

14. Lindblade KA, Gimnig JE, Kamau L, Hawley WA, Odhiambo F, Olang G, et al.: Impact of Sustained Use of Insecticide-Treated Bednets on Malaria Vector Species Distribution and Culicine Mosquitoes. Journal of Medical Entomology 2006, 43(2):428-32.

15. Moiroux N, Gomez MB, Pennetier C, Elanga E, Djènontin A, Chandre F, et al.: Changes in anopheles funestus biting behavior following universal coverage of long-lasting insecticidal nets in benin. Journal of Infectious Diseases 2012; 206(10):1622-9. 
16. Russell TL, Govella NJ, Azizi S, Drakeley CJ, Kachur SP, Killeen GF.: Increased proportions of outdoor feeding among residual malaria vector populations following increased use of insecticide-treated nets in rural Tanzania. Malaria journal 2011, 10(1):80.

17. Thomson $H$, Thomas $S$, Sellstrom E, Petticrew M.: Housing improvements for health and associated socio-economic outcomes. The Cochrane database of systematic reviews. 2013;2(2):CD008657.

18. Hackett LW.: Malaria in Europe - An Ecological Study. Oxford University Press, 1937.

19. Celli A.: The New Preventative Treatment of malaria in Latium.Collected Papers on Malaria 18991912. London: London School of Hygiene \& tropical Medicine; 1901:1-12.

20. Ghebreyesus T a, Haile M, Witten KH, Getachew a, Yohannes M, Lindsay SW, et al.: Household risk factors for malaria among children in the ehtiopian highlands. Transactions of the Royal Society of Tropical Medicine and Hygiene 2000, 94(1):17-21.

21. Lindsay SW, Schellenberg JRMA, Zeiler HA, Daly RJ, Salum FM, Wilkins HA.: Exposure of Gambian children to Anopheles gambiae malaria vectors in an irrigated rice production area.Medical and Veterinary Entomology 1995, 9(1):50-8.

22. Lindsay SW, Emerson PM, Charlwood JD.: Reducing malaria by mosquito-proofing houses. Trends in Parasitology 2002, 18(11):510-4.

23. Temu EA, Coleman M, Abilio AP, Kleinschmidt I.: High prevalence of malaria in Zambezia, Mozambique: The protective effect of IRS versus increased risks due to pig-keeping and house construction.PLOS ONE. 2012;7(2).

24. Kirby MJ, Ameh D, Bottomley C, Green C, Jawara M, Milligan PJ, et al.: Effect of two different house screening interventions on exposure to malaria vectors and on anaemia in children in The Gambia: a randomised controlled trial. The Lancet. 2009,374(9694):998-1009.

25. Lindsay SW, Jawara M, Paine K, Pinder M, Walraven GEL, Emerson PM.: Changes in house design reduce exposure to malaria mosquitoes. Tropical Medicine \& International Health. 2003, 8(6):512517.

26. Sinka ME, Bangs MJ, Manguin S, Coetzee M, Mbogo CM, Patil AP, et al.: The dominant Anopheles vectors of human malaria in Africa, Europe and the Middle East: occurrence data, distribution maps and bionomic précis. Parasites \& Vectors. 2011, 4(1):89.

27. Huho B, Briët O, Seyoum A, Sikaala C, Bayoh N, Gimnig J, et al.: Consistently high estimates for the proportion of human exposure to malaria vector populations occurring indoors in rural Africa.International Journal of Epidemiology 2013, 42(1):235-47.

28. Bradley J, Rehman AM, Schwabe C, Vargas D, Monti F, Ela C, et al. Reduced prevalence of malaria infection in children living in houses with window screening or closed eaves on Bioko Island, Equatorial Guinea.PLOS ONE 2013, 8(11):1-7.

29. Lwetoijera DW, Kiware SS, Mageni ZD, Dongus S, Harris C, Devine GJ, et al.: A need for better housing to further reduce indoor malaria transmission in areas with high bed net coverage. Parasites \& Vectors 2013,6(1):57. 
30. Lindsay SW, Jawara M, Paine K, Pinder M, Walraven GEL, Emerson PM.: Changes in house design reduce exposure to malaria mosquitoes. Tropical Medicine and International Health 2003, 8(6):5127.

31. Animut A, Balkew M, Lindtjørn B.: Impact of housing condition on indoor-biting and indoor-resting Anopheles arabiensis density in a highland area, central Ethiopia.Malaria Journal 2013, 12(1):393.

32. Kirby MJ, West PA, Green C, Jasseh M, Lindsay SW.: Risk factors for houseentry by culicine mosquitoes in a rural town and satellite villages in The Gambia.Parasites and Vectors 2008,1:41.

33. Pinder M, Conteh L, Jeffries D, Jones C, Knudsen J, Kandeh B, et al.: The RooPfs study to assess whether improved housing provides additional protection against clinical malaria over current best practice in The Gambia: study protocol for a randomized controlled study and ancillary studies. Trials 2016, 17(1):275.

34. Snyman K, Mwangwa F, Bigira V, Kapisi J, Clark TD, Osterbauer B, et al.: Poor housing construction associated with increased malaria incidence in a cohort of young Ugandan children.American Journal of Tropical Medicine and Hygiene 2015, 92(6):1207-13.

35. Nkuo-Akenji T, Ntonifor N, Ndukum M, Kimbi H, Abongwa E, Nkwescheu A, et al.: Environmental factors affecting malaria parasite prevalence in rural Bolifamba, South- West Cameroon.African Journal of Health Sciences 2008, 13(1):40-6.

36. Bissaya R, Ghogomu RT, Moundi A, Njom B, Kanouo S.: Utilisation des données géologiques et gestion des informations multi-sources pour l'analyse de l' aléa glissement de terrain / éboulement dans le secteur Nord-Ouest de la région de Yaoundé Résumé. Afrique Science 2014, 10(3):113-33.

37. Golda Danielle NE.: agronomiques. NDO Eunice Golda Danièle. 2011.

38. Wonghi DJN. : Policy brief on ,scaling up malaria control interventions in cameroon. 2010;8.

39. Gillies MT, De Meillon B: The Anophelinae of Africa South of the Sahara. 1947. 344 p.

40. Gillies MT, Coetzee M: A Supplement to the Anophelinae of Africa South of the Sahara (Afrotropical region) Johanesbourg: The South African Institute of tropical research; 1987.

41. Detinova T S.: Age grouping methods in Diptera of medical importance, with special reference to some vectors of malaria.Vol. 47, World Health Organization, monograph series, 1962, 47: 216.

42. Cox RA.: Methods in Enzymology.Academic Press, Orlando 1968, 12:120-9.

43. Favia GA, della Torre A, Bagayoko M, A L, Sagnon N, Touré Y, et al. Molecular identification of sympatric chromosomal forms of Anopheles gambiae and further evidence of their reproductive isolation.Insect Molecular Biology 1997, 6(4):377-83.

44. RA W, F Z, Y C, GH C, TR B, I S, et al.: Comparative testing of Plasmodium falciparum sporozoite monoclonal antibodies for ELISA development.Bull World Health Organ. 198,,65:39-45.

45. Burkot TR, Williams JL SI.: Identification of Plasmodium falciparum- infected mosquitoes by a double antibody enzyme-linked immunosorbent assay. American Journal of Tropical Medicine and Hygiene 1984, 33:783-8. 
46. Ogoma SB, Lweitoijera DW, Ngonyani H, Furer B, Russell TL, Mukabana WR, et al.: Screening Mosquito House Entry Points as a Potential Method for Integrated Control of Endophagic Filariasis, Arbovirus and Malaria Vectors.PLoS Neglected Tropical Diseases 2010,4:e773.

47. Bigoga JD, Manga $L$, Titanji VP, Coetzee $M$, Leke RG.: Malaria vectors and transmission dynamics in coastal south-western Cameroon. Malaria Journal 2007,6(1):5.

48. Bigoga JD, Nanfack FM, Awono-Ambene PH, Patchoké S, Atangana J, Otia VS, et al.: Seasonal prevalence of malaria vectors and entomological inoculation rates in the rubber cultivated area of Niete, South Region of Cameroon.Parasites and Vectors 2012, 5:197.

49. Ayala D, Costantini C, Ose K, Kamdem GC, Antonio-Nkondjio C, Agbor J-P, et al.: Habitat suitability and ecological niche profile of major malaria vectors in Cameroon.Malaria Journal. 2009, 8:307.

50. Antonio-Nkondjio C, Awono-Ambene P, Chouaibou M, Tchuinkam T, Fontenille D, Kerah C, et al.: Complexity of the malaria vectorial system in Cameroon: contribution of secondary vectors to malaria transmission. Journal of medical entomology 2006, 43(6):1215-1221.

51. Tusting LS, Ippolito MM, Willey BA, Kleinschmidt I, Dorsey G, Gosling RD, et al.: The evidence for improving housing to reduce malaria: a systematic review and meta-analysis. Malaria Journal. 2015; doi: 11.86/s12936-015-07246-1.

52. Atieli $H$, Menya $D$, Githeko A, Scott T.: House design modifications reduce indoor resting malaria vector densities in rice irrigation scheme area in western Kenya.Malaria Journal 2009, 8(1):108.

53. Kampango A, Bragança M, Sousa B de, Charlwood JD.: Netting barriers to prevent mosquito entry into houses in southern Mozambique: a pilot study.Malaria journal 2013, 12:99.

54. Ogoma SB, Kannady K, Sikulu M, Chaki PP, Govella NJ, Mukabana WR, et al.: Window screening, ceilings and closed eaves as sustainable ways to control malaria in Dar es Salaam, Tanzania.Malaria Journal 2009, 8(1):221.

\section{Tables}

Table 1: Malaria transmission indices in Minkoameyos 


\begin{tabular}{|c|c|c|c|c|c|c|c|}
\hline \multicolumn{2}{|c|}{ Entomological index } & \multicolumn{6}{|c|}{ Anopheles species } \\
\hline & & \multirow[t]{2}{*}{ An. brohieri } & \multirow{2}{*}{\begin{tabular}{|l|} 
An. \\
funestus \\
\end{tabular}} & \multirow{2}{*}{\begin{tabular}{|l|} 
An. \\
gambiae \\
\end{tabular}} & \multirow[t]{2}{*}{ An. ziemanni } & \multirow{2}{*}{\begin{tabular}{|l|} 
An. \\
paludis \\
\end{tabular}} & \multirow{2}{*}{\begin{tabular}{|l|} 
Total \\
Anopheles
\end{tabular}} \\
\hline & & & & & & & \\
\hline \multirow[t]{2}{*}{ Composition } & $\mathbf{n}$ & 8 & 19 & 616 & 1 & 3 & 647 \\
\hline & $\%$ & 1.2 & 2.9 & 95.2 & 0.2 & 0.5 & 100 \\
\hline \multicolumn{2}{|c|}{ Man biting rate(b/p/n) } & 0.001 & 0.003 & 0.094 & 0 & 0 & 0.098 \\
\hline \multicolumn{2}{|c|}{ Parous/Dissected } & $1 / 8$ & $7 / 13$ & $290 / 465$ & $1 / 1$ & $0 / 1$ & $299 / 488$ \\
\hline \multirow[t]{2}{*}{ Parity rate } & $\%$ & 12.5 & 53.8 & 62.4 & 100 & 0 & 61.3 \\
\hline & $(95 \% \mathrm{Cl})$ & $(0.3-52.7)$ & $(25.1-80.8)$ & (57.8-66.8) & $n / a$ & $n / a$ & $(56.8-65.6)$ \\
\hline \multicolumn{2}{|c|}{$\begin{array}{l}\text { Tested for CSP } \\
\end{array}$} & 8 & 19 & 584 & 1 & 3 & 615 \\
\hline \multirow[t]{2}{*}{ ICS rate } & $\%$ & 0 & 52.6 & 33.7 & 100 & 100 & 34.2 \\
\hline & $(95 \% \mathrm{Cl})$ & $n / a$ & $(28.9-75.6)$ & $(29.9-37.7)$ & $n / a$ & $n / a$ & $(30.4-38.1)$ \\
\hline EIR (ib/p/n) & $\%$ & & 0.01 & 0.28 & 0 & 0 & 0.29 \\
\hline
\end{tabular}

\section{n/a: Not applicable}

Table 2: Effect of housing improvement on malaria transmission indices in Minkoameyos

\begin{tabular}{|c|c|c|c|c|c|c|c|c|c|c|}
\hline \multirow{3}{*}{ Mosquito specy } & \multicolumn{4}{|c|}{ Improved houses } & \multicolumn{4}{|c|}{ Unimproved houses } & \multirow[t]{3}{*}{ IE } & \multirow[t]{3}{*}{ P-value } \\
\hline & \multicolumn{3}{|c|}{ Number of Anopheles } & \multirow[t]{2}{*}{ RFI } & \multicolumn{3}{|c|}{ Number of Anopheles } & \multirow[t]{2}{*}{ RFN } & & \\
\hline & Indoor & Outdoor & Tota & & Indoor & Outdoor & Total & & & \\
\hline All Anopheles & 86 & 343 & 429 & 3.99 & 68 & 150 & 218 & 2.21 & 1.8 & 0.001 \\
\hline An. funestus & 1 & 12 & 13 & 12 & 3 & 3 & 6 & 1 & 12 & 0.07 \\
\hline An. gambiae & 84 & 320 & 404 & 3.81 & 65 & 147 & 212 & 2.26 & 1.7 & 0.004 \\
\hline Other Anopheles & 1 & 11 & 12 & 11 & 0 & 0 & 0 & 0 & $n / a$ & $n / a$ \\
\hline
\end{tabular}

\section{n/a: Not applicable}

Table 3 : Effect of housing improvement on parity rate of Anopheles population 


\begin{tabular}{|c|c|c|c|c|c|c|c|c|c|c|c|}
\hline \multirow[t]{2}{*}{ Mosquito specy } & \multirow[t]{2}{*}{ Factor } & \multicolumn{4}{|c|}{ Improved houses } & \multicolumn{4}{|c|}{ Unimproved houses } & \multirow[t]{2}{*}{ IE } & \multirow[t]{2}{*}{ P-value } \\
\hline & & Indoor & Outdoor & Total & RFI & Indoor & Outdoor & Total & RFN & & \\
\hline \multirow[t]{2}{*}{ All Anopheles } & Parous (n) & 31 & 139 & 170 & 4.48 & 35 & 94 & 129 & 2.67 & 1.7 & 0.05 \\
\hline & Parity rate (\%) & 43.1 & 59.6 & 55.74 & 1.39 & 62.5 & 74.02 & 70.49 & 1.18 & 1.2 & $\mathrm{n} / \mathrm{a}$ \\
\hline \multirow[t]{2}{*}{ An. funestus } & Parous (n) & 1 & 4 & 5 & 4 & 0 & 2 & 2 & $\mathrm{n} / \mathrm{a}$ & $n / a$ & $n / a$ \\
\hline & Parity rate (\%) & 100 & 66.6 & 71.43 & 0.67 & 0 & 66.6 & 33.33 & $n / a$ & $n / a$ & $n / a$ \\
\hline \multirow[t]{2}{*}{ An. gambiae } & Parous (n) & 29 & 134 & 163 & 4.62 & 35 & 92 & 127 & 2.63 & 1.8 & 0.03 \\
\hline & Parity rate (\%) & 41.4 & 61.4 & 56.6 & 1.48 & 66.04 & 74.2 & 71.75 & 1.12 & 1.3 & $\mathrm{n} / \mathrm{a}$ \\
\hline \multirow[t]{2}{*}{ Other Anopheles } & Parous (n) & 1 & 1 & 2 & 1 & 0 & 0 & 0 & $\mathrm{n} / \mathrm{a}$ & $\mathrm{n} / \mathrm{a}$ & $n / a$ \\
\hline & Parity rate (\%) & 100 & 11.1 & 20 & 0.11 & $n / a$ & $\mathrm{n} / \mathrm{a}$ & $\mathrm{n} / \mathrm{a}$ & $\mathrm{n} / \mathrm{a}$ & $n / a$ & $\mathrm{n} / \mathrm{a}$ \\
\hline
\end{tabular}

n/a: Not applicable

Table 4: Effect of housing improvement on indoor and outdoor EIR of Anopheles

\begin{tabular}{|c|c|c|c|c|c|c|c|c|c|c|c|}
\hline \multirow[t]{2}{*}{ Mosquito specy } & \multirow[t]{2}{*}{ Factor } & \multicolumn{4}{|c|}{ Improved houses } & \multicolumn{4}{|c|}{ Unimproved houses } & \multirow[t]{2}{*}{ IE } & \multirow[t]{2}{*}{ P-value } \\
\hline & & Indoor & Outdoor & TOTAL & RFI & Indoor & Outdoor & TOTAL & RFN & & \\
\hline All Anophes & EIR (ib/p/n) & 1.67 & 8.07 & 0.048 & 4.84 & 1.24 & 3.49 & 2.34 & 2.81 & 1.7 & $\mathrm{n} / \mathrm{a}$ \\
\hline An. funestus & EIR (\%) & 0 & 75 & 69.23 & 0 & 33.33 & 0 & 17 & $\mathrm{n} / \mathrm{a}$ & $n / a$ & $\mathrm{n} / \mathrm{a}$ \\
\hline An. gambiae & EIR (ib/p/n) & 1.64 & 7.77 & 0.047 & 4.75 & 1.13 & 3.43 & 2.24 & 3.04 & 1.6 & $\mathrm{n} / \mathrm{a}$ \\
\hline Other Anopheles & EIR (\%) & 0.007 & 0.48 & 0.001 & 60.5 & $n / a$ & $\mathrm{n} / \mathrm{a}$ & $n / a$ & $\mathrm{n} / \mathrm{a}$ & $n / a$ & $\mathrm{n} / \mathrm{a}$ \\
\hline
\end{tabular}

n/a: Not applicable

\section{Figures}




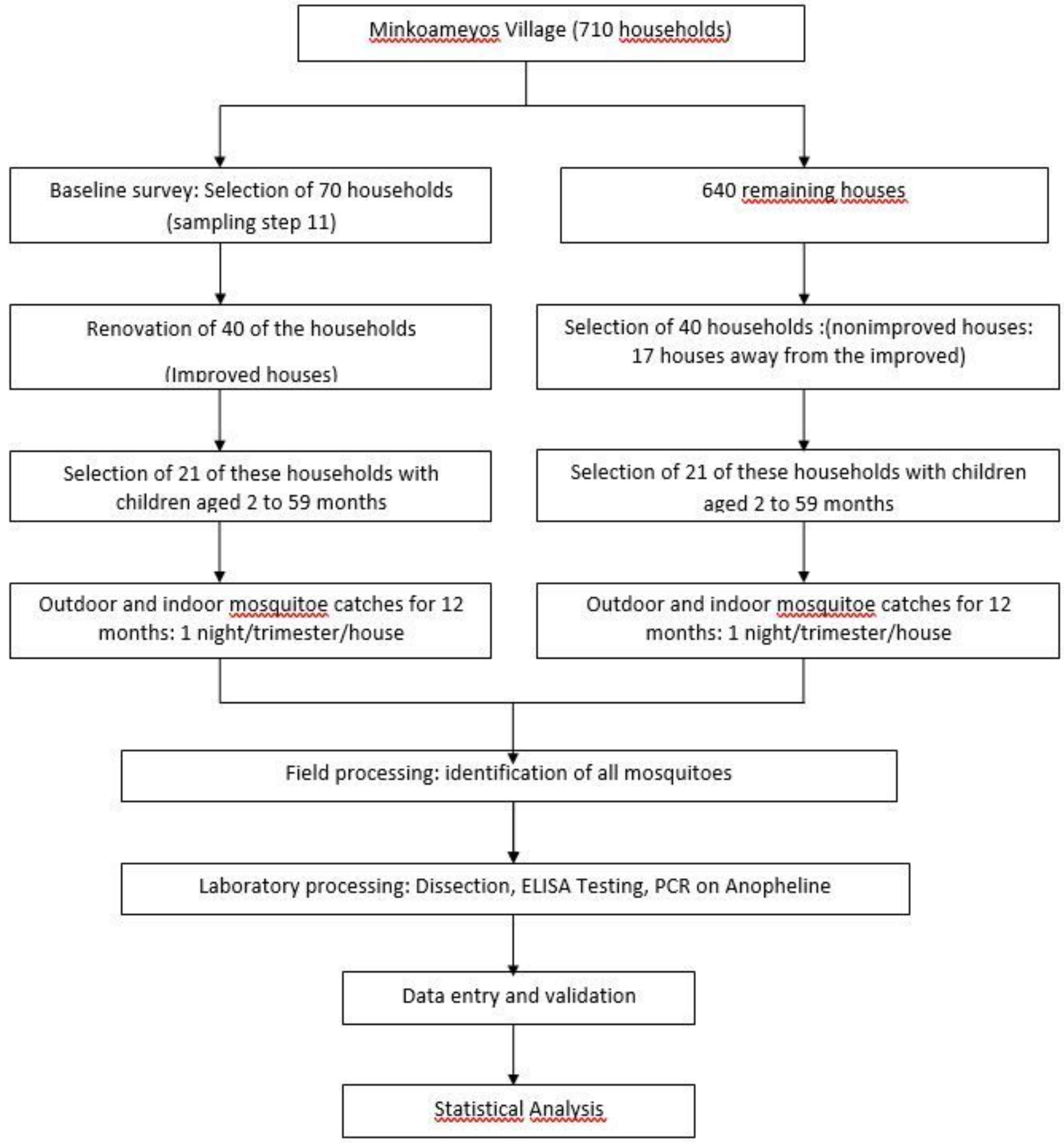

\section{Figure 1}

Sampling and data collection process for the entomologic study 


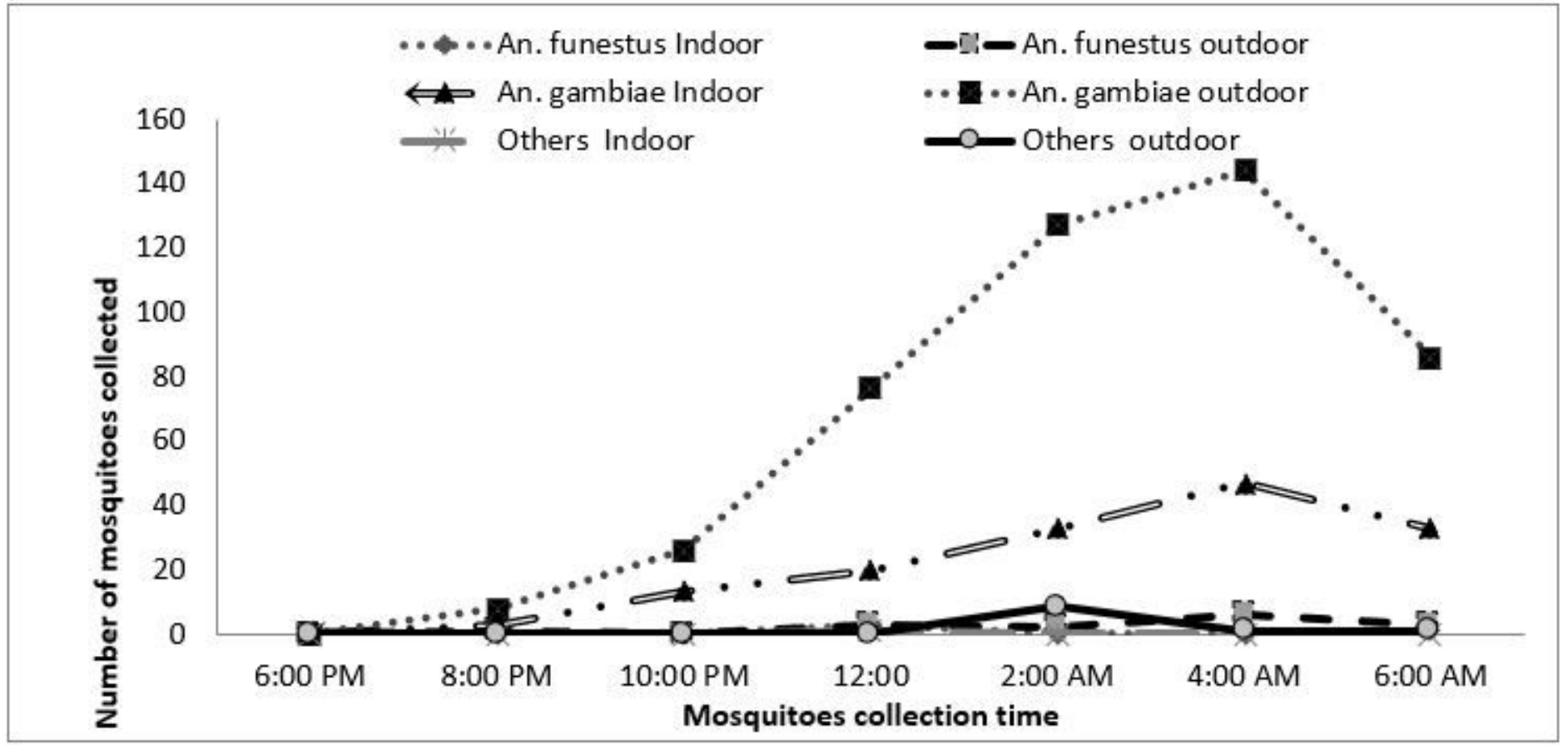

Figure 2

Indoor and outdoor biting cycles of Anopheles species in Minkoameyos

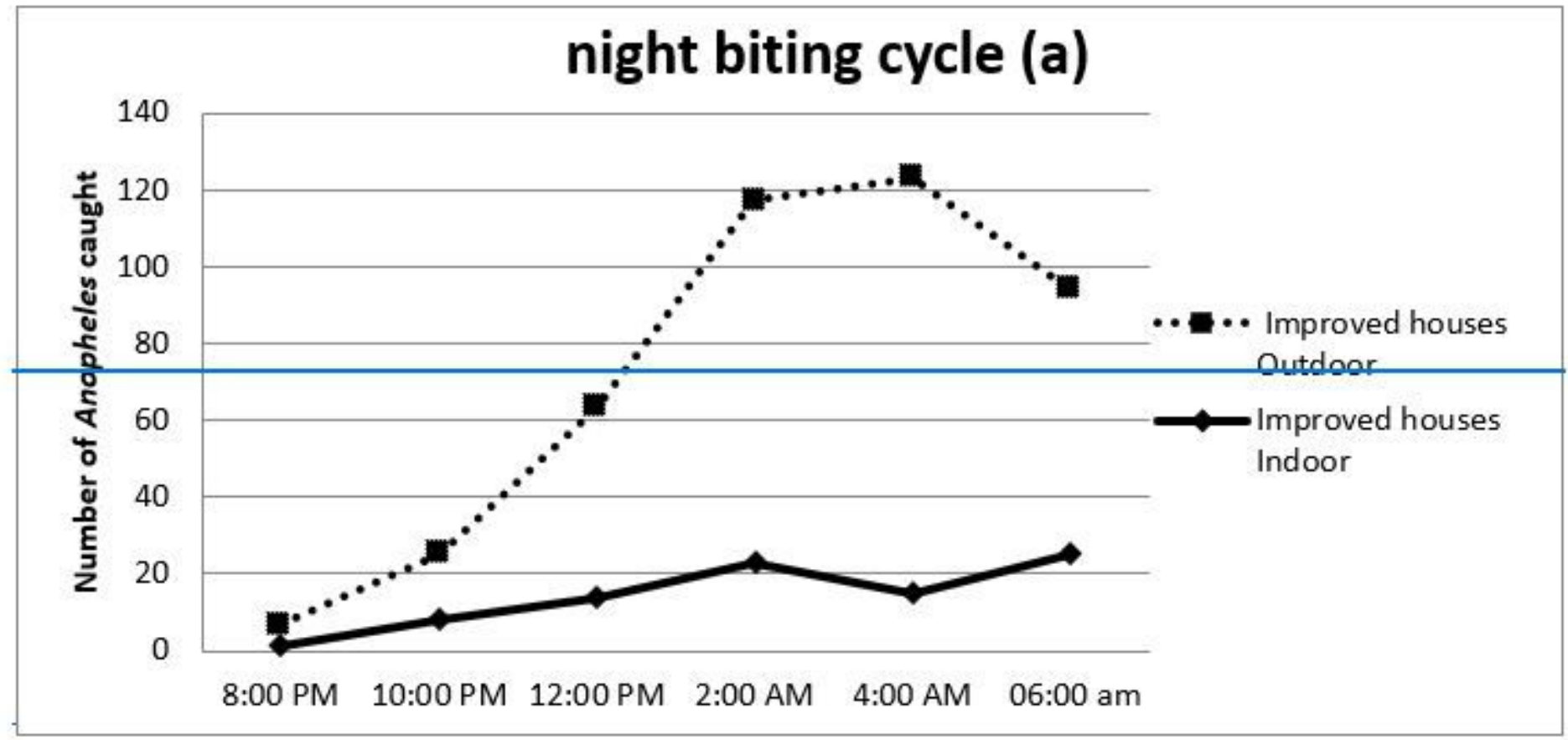

Figure 3

Night biting cycle of the anopheles in improved houses 


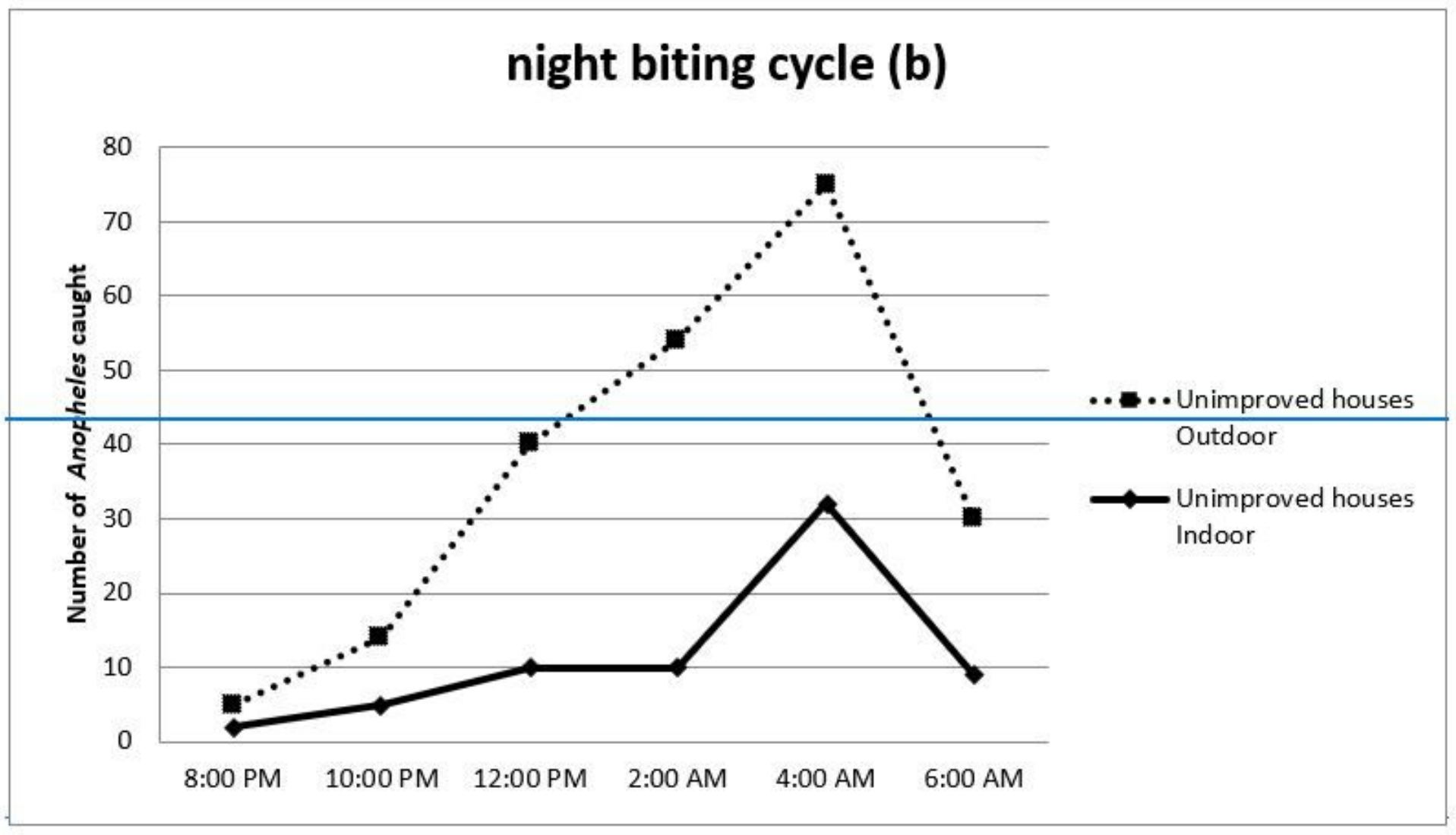

Figure 4

Night biting cycle of the anopheles in the Unimproved houses

\section{Supplementary Files}

This is a list of supplementary files associated with this preprint. Click to download.

- Supportinginformation.docx 